\title{
Single Molecule Discrimination of Heteropolytungstates and their Isomers in Solution with a Nanometer-Scale Pore_Supplementary Information
}

\author{
Jessica Ettedgui ${ }^{1,2,},{ }^{*}$, John J. Kasianowicz ${ }^{1}$ and Arvind Balijepalli ${ }^{1}$
}

1) Engineering Physics Division, Physical Measurement Laboratory, National Institute of Standards and Technology, Gaithersburg, MD 20899

2) Columbia University, Department of Chemical Engineering, New York, NY 10027-6623

We present below experimental results that illustrate the how the capture rate of POMs by the $\alpha H L$ nanopore varies with the POM concentration and the applied potential. Also shown are the complete $\mathrm{pH}$-dependent NMR spectra of an aqueous POM solution.

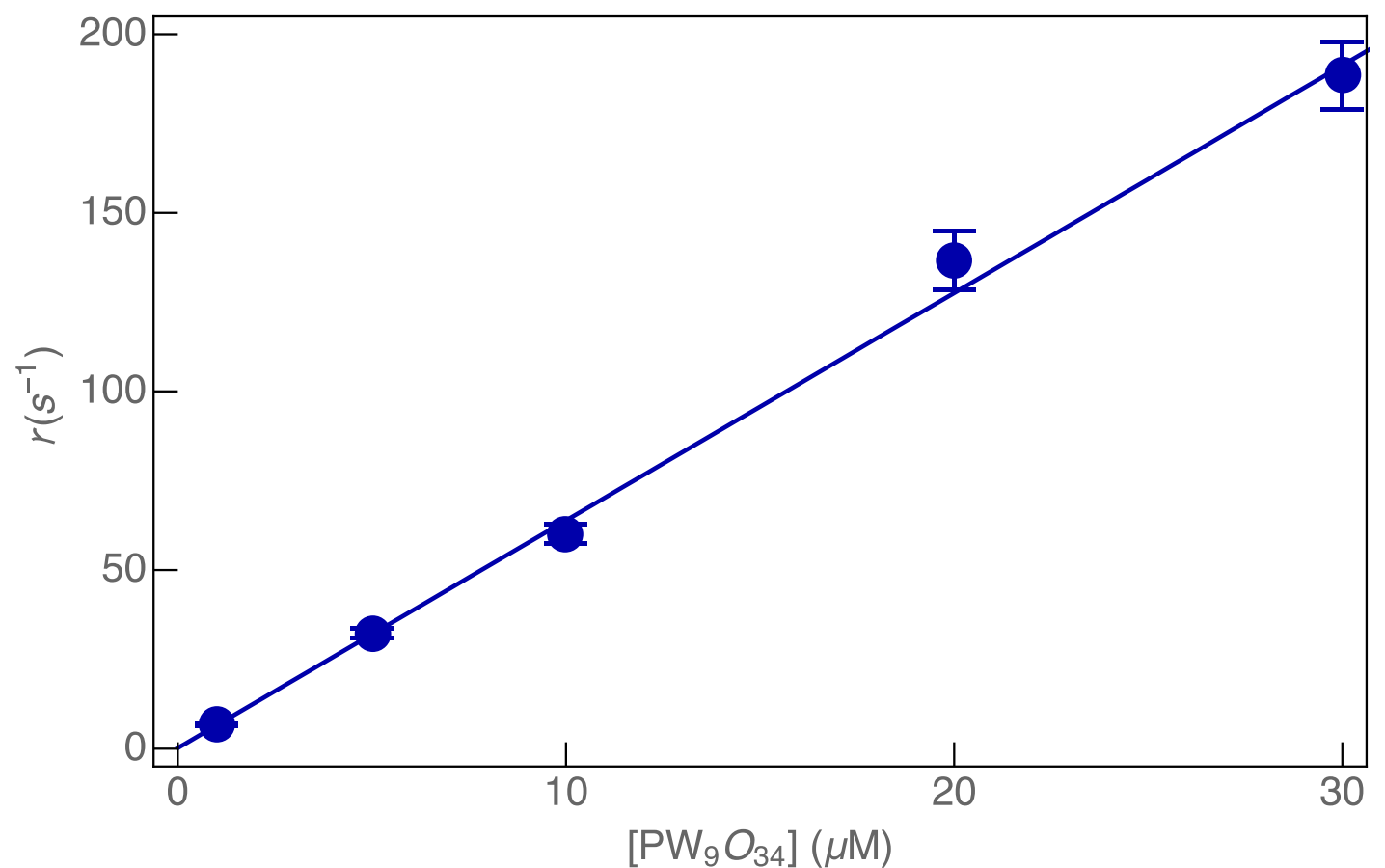

SI1: POM capture rate by the $\alpha-\mathrm{HL}$ pore as a function of POM concentration at V=120 $\mathrm{mV}$.

The capture rate of POMs by the alpha-hemolysin nanopore increases in direct proportion to the POM concentration. The error bars correspond to the standard deviation in each measurement. The slope of a linear least squares fit to the data is $6.4 \mu \mathrm{M}^{-1} \mathrm{~s}^{-1}$. 


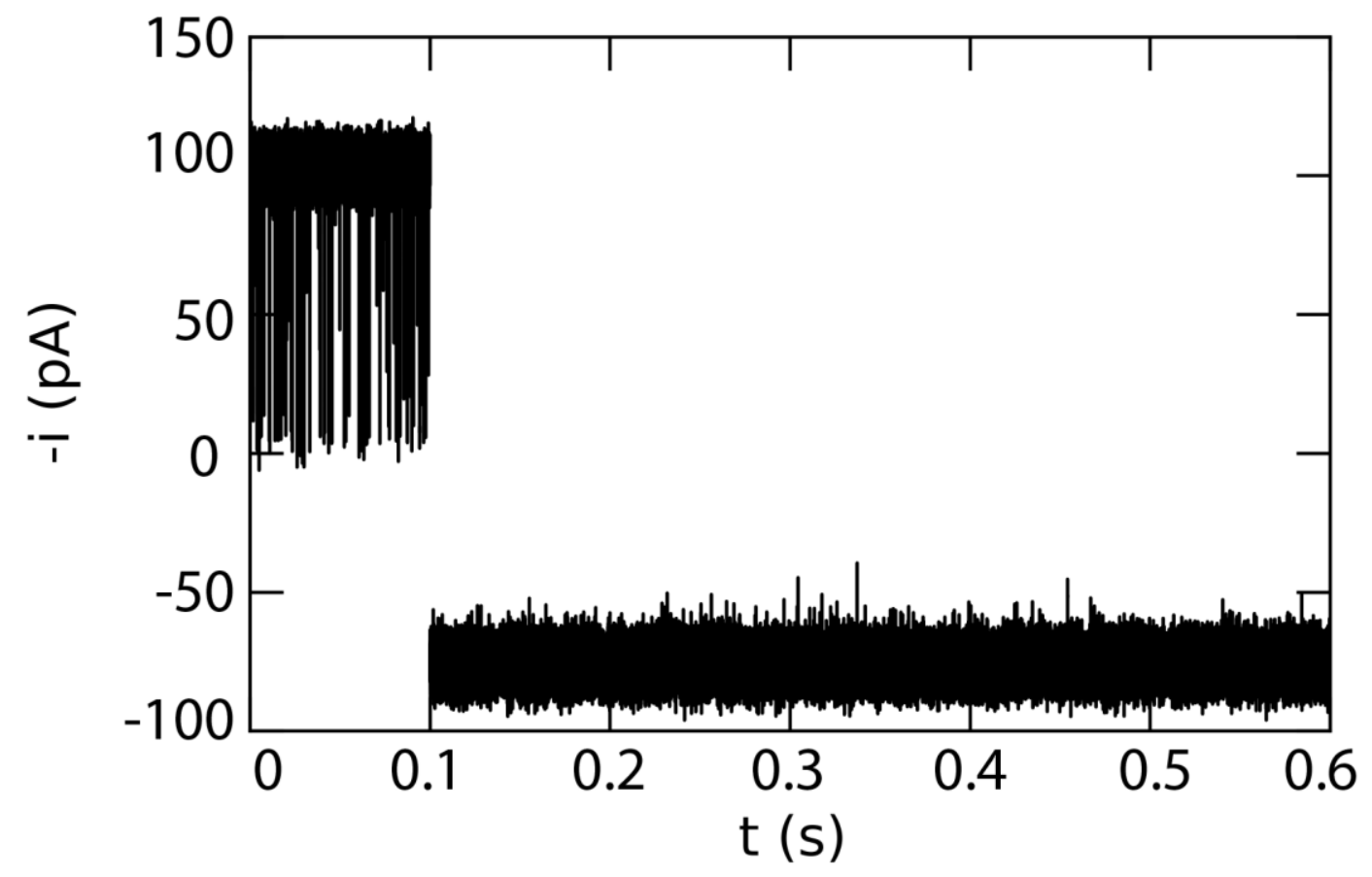

SI2: POMs only enter the pore with positive but not negative applied potentials. Ionic current time series at $120 \mathrm{mV}$ and $-120 \mathrm{mV}$.

Positive potentials drive cations from the trans to the cis side of the membrane. Thus, a positive potential is expected to force negatively-charged POMs in the cis compartment into the pore. Reversing the polarity should exclude POMs from the pore. Both results are borne out experimentally 


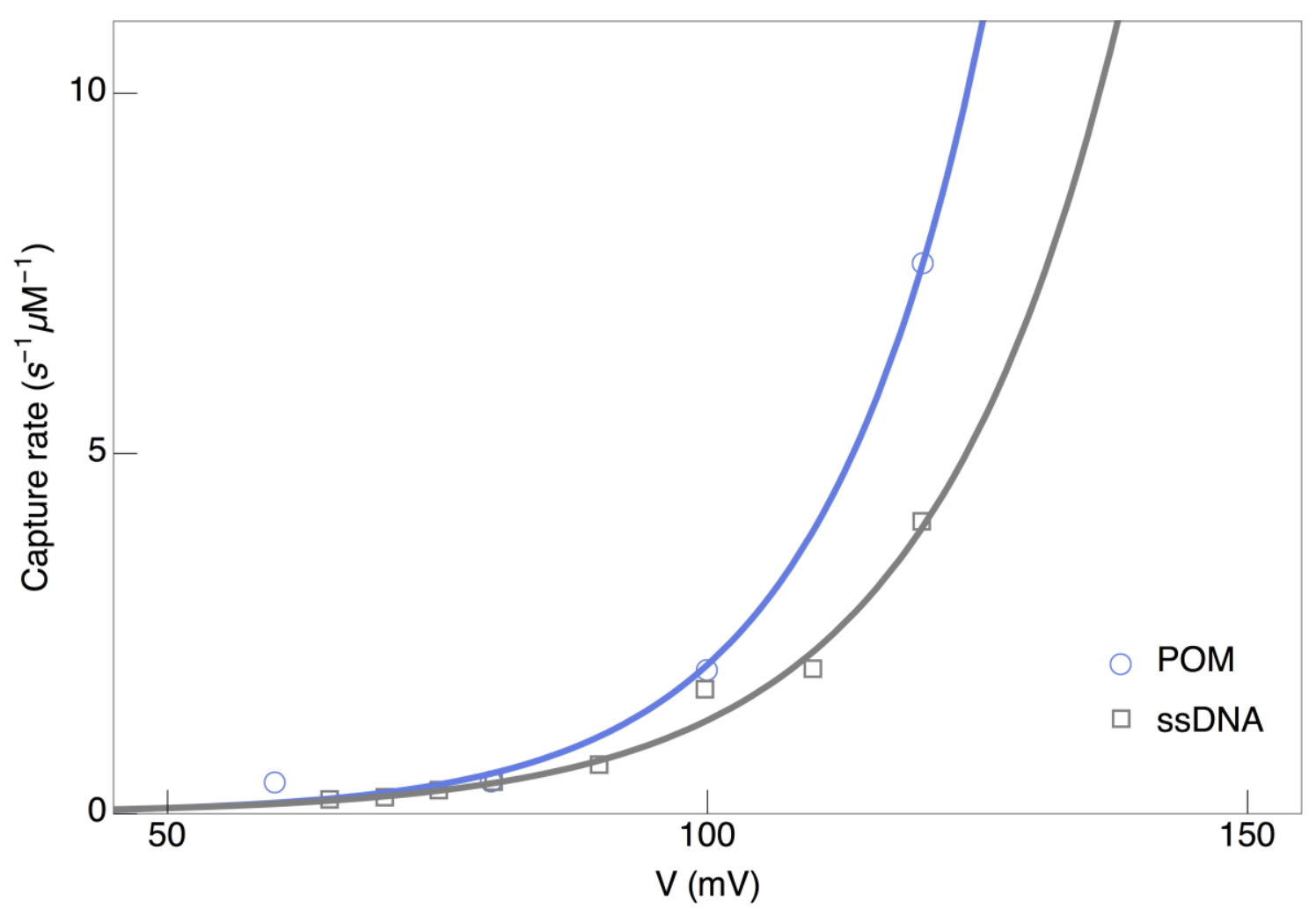

SI3: Capture rate of POMs and single-stranded DNA (ssDNA) as a function of the applied potential.

The POM capture rate increases nonlinearly with increasing applied potential (open circles): $0.47 \pm 0.002,0.48 \pm 0.001,2.03 \pm 0.005$, and $7.67 \pm 0.002 \mathrm{~s}^{-1} \mu \mathrm{M}^{-1}$ for $V=60,80,100$, and 120 $\mathrm{mV}$, respectively. A similar effect was demonstrated for single-stranded DNA (open squares) ${ }^{1}$ The lines are the least squares fits of exponential functions to the data. The results suggest that the entry of POMs into the pore is limited by an energy barrier. The physical basis of the energy barrier for the POMs is not known. 


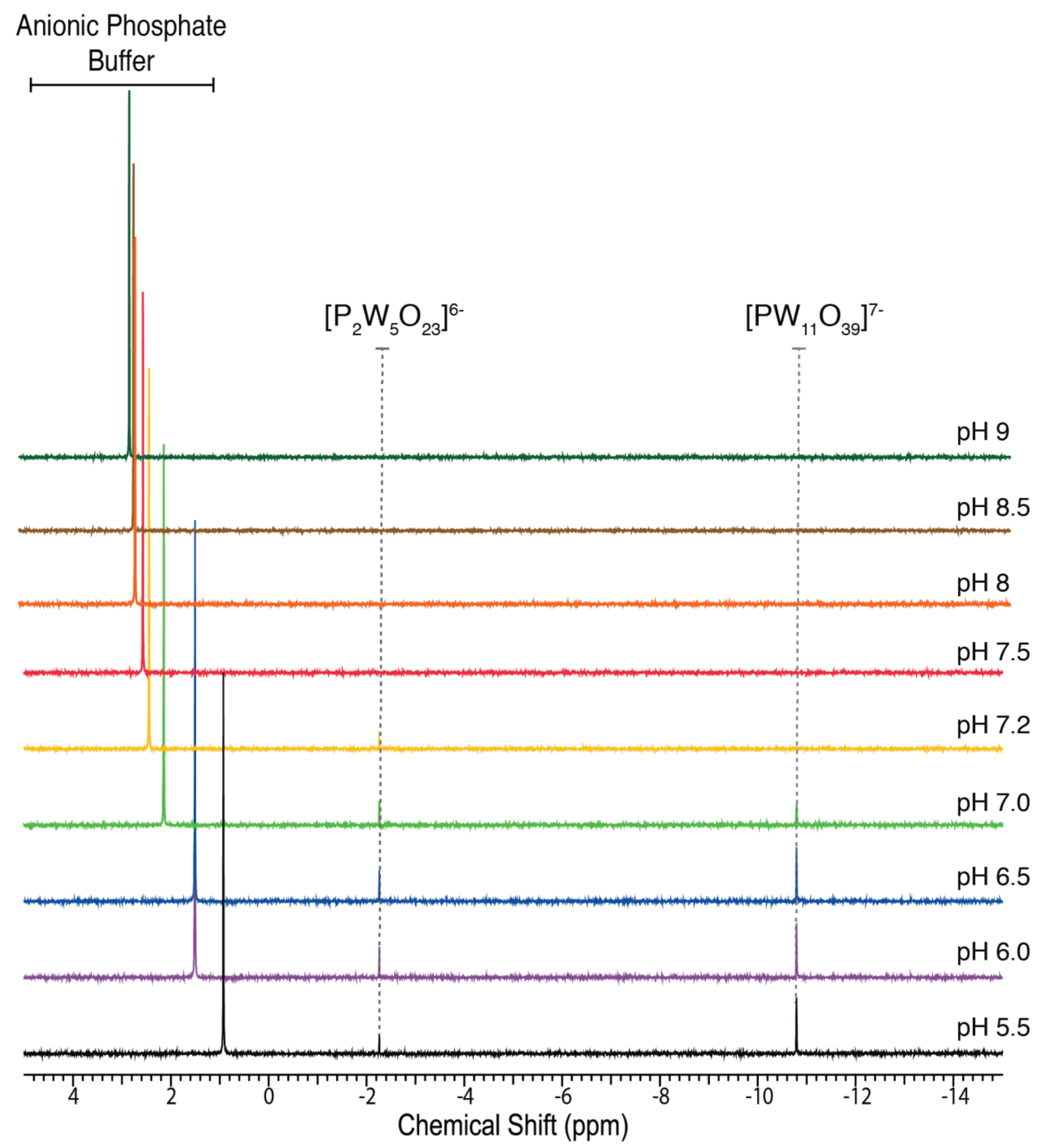

SI4: $\mathrm{pH}$ dependence of the POMs with $2 \mathrm{mM}$ concentration in aqueous solution monitored by NMR.

The largest peaks in $S I 3$ correspond to protonated phosphate anions in the solution buffer. These peaks shift monotonically with $\mathrm{pH}$ from $\delta=+1.6 \mathrm{ppm}(\mathrm{pH} 5.5)$ to $\delta=+3.53 \mathrm{ppm}(\mathrm{pH}$ ). The minor peaks, shown in detail in the paper, show that an increase in $\mathrm{pH}$ decreases the primary species $\left[\mathrm{PW}_{11} \mathrm{O}_{39}\right]^{7-}(\delta=-10.02 \mathrm{ppm})$ and increases a $\mathrm{POM}$ species that is consistent with $\left[\mathrm{P}_{2} \mathrm{~W}_{5} \mathrm{O}_{23}\right]^{6-}(\delta=-1.5 \mathrm{ppm})$. 


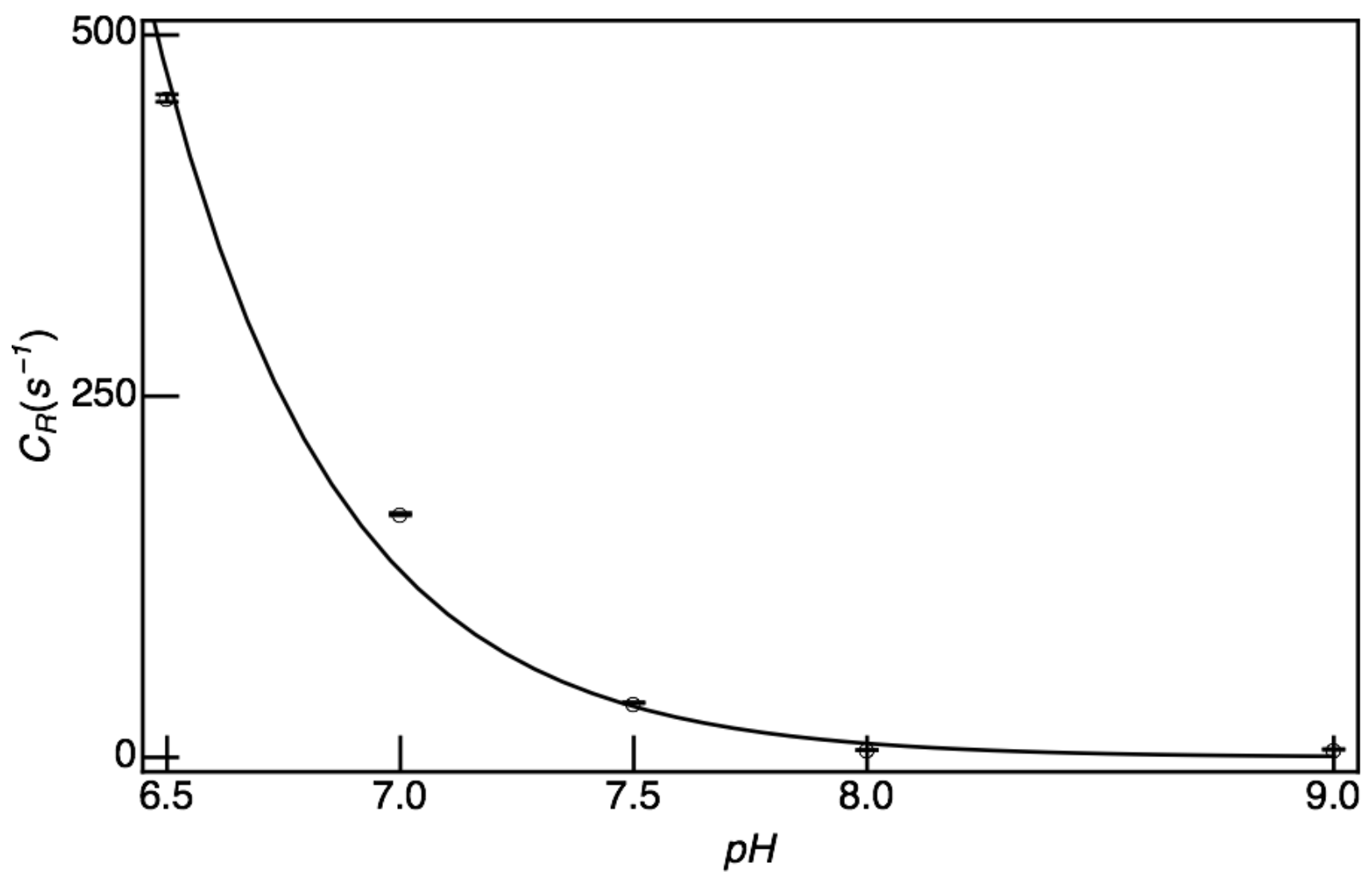

SI5: $\mathrm{pH}$ dependence of the POM capture rate by the $\alpha-\mathrm{HL}$ pore.

The apparent POM concentration decreases nonlinearly with increasing $\mathrm{pH}$. Because the capture rate scales in proportion to the free POM concentration, the latter can be estimated by a capture rate measurement. 

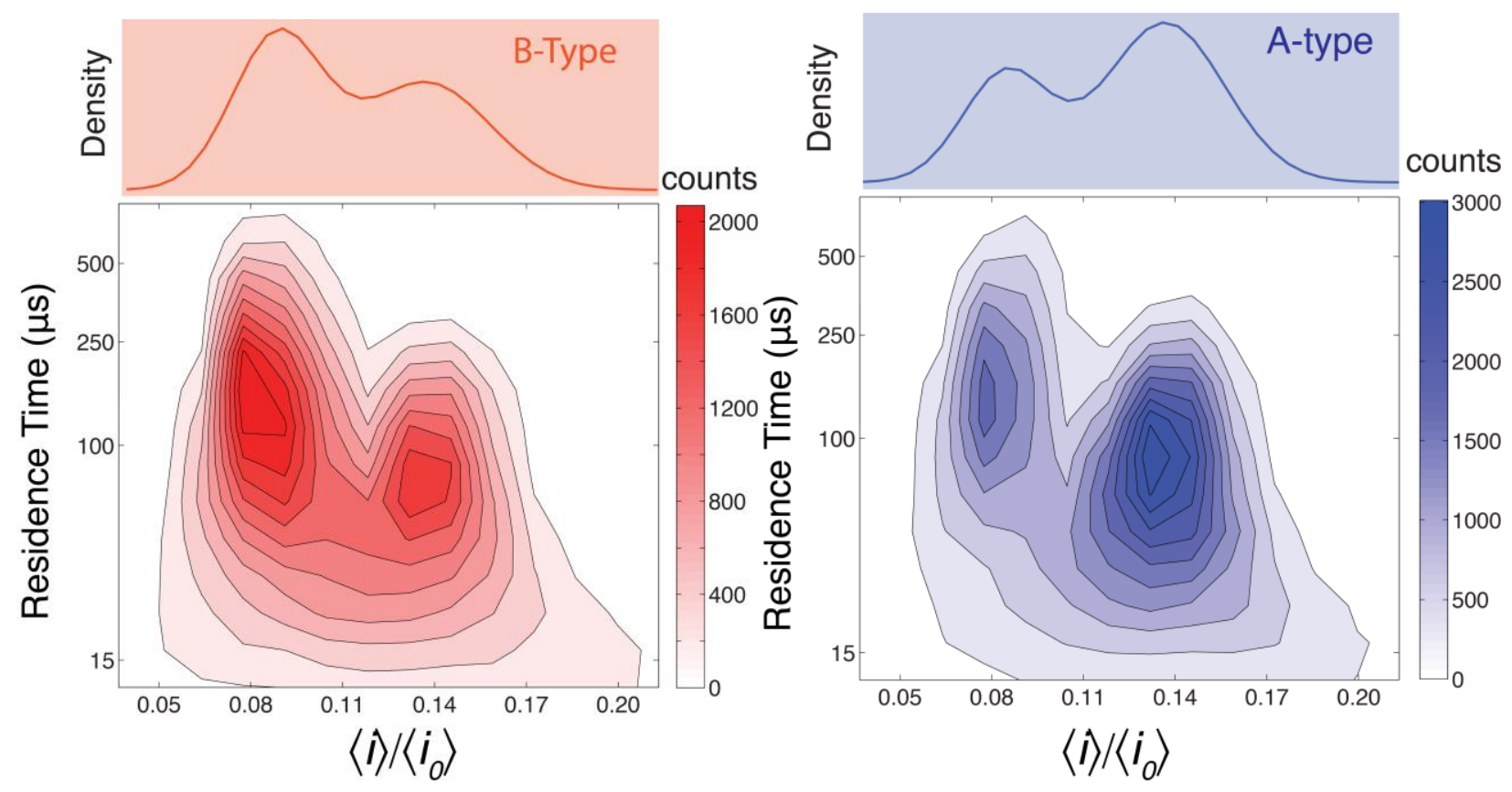

SI6: 3D density plots of residence time as a function of blockade depth of the type A and Bisomers of the trivacant Keggin structure $\left[\mathrm{PW}_{9} \mathrm{O}_{34}\right]^{9-}$

The density plot represents heat plots of the residence time - relative to the blockade depths ratio for all the events caused by predominately A-type (left) and B-type (right) isomers of $\mathrm{PW}_{9} \mathrm{O}_{34}$ in aqueous solution show that the mean residence times for the isomers, estimated from their distributions, differ by nearly a factor of 2 (Type A $(117 \pm 2) \mu$ s and Type B $(65 \pm 1) \mu s)$. 


\section{Materials and Methods}

Reagents were obtained as follows: phospholipid 1,2-diphytanoyl-sn-glycero-3-phosphocholine (DPhPC; Avanti Polar Lipids, Alabaster, AL), pre-formed wild-type $\alpha$-HL heptamer (from Columbia University, NY), decane, Sodium chloride $(\mathrm{NaCl})$, sodium phosphate monobasic $\left(\mathrm{NaH}_{2} \mathrm{PO}_{3}\right)$, phosphotungstic acid $\left(\mathrm{H}_{3} \mathrm{PW}_{12} \mathrm{O}_{40}\right)$, orthophosphoric acid $\left(\mathrm{H}_{3} \mathrm{PO}_{4}\right)$, sodium tungstate $\left(\mathrm{Na}_{2} \mathrm{WO}_{4} \cdot 2 \mathrm{H}_{2} \mathrm{O}\right)$ acetic acid (all from Sigma-Aldrich), were purchased from commercial suppliers and used without further purification.

All ${ }^{31} \mathrm{P}$ experiments were performed in $5 \mathrm{~mm}$ o.d. tubes, on a Bruker Avance III HD $800 \mathrm{MHz}$ spectrometer equipped with a CPQCI probe. Pulse program was zg30 with $31 \mathrm{P}$ set as the observing channel. The number of scans was 160 , relaxation delay D1 was $10 \mathrm{~s}$, and sample temperature was $298.1 \mathrm{~K}$. The chemical shifts are given according to the IUPAC convention with respect to $85 \% \mathrm{H}_{3} \mathrm{PO}_{4}$.

Preparation and characterization of $\mathrm{A}-\mathrm{Na}_{8} \mathrm{HPW}_{9} \mathrm{O}_{34}$ A- $\mathrm{Na}_{8} \mathrm{HPW}_{9} \mathrm{O}_{34}$ was synthetized according to published method ${ }^{2}$. Orthophosphoric acid, $\mathrm{H}_{3} \mathrm{PO}_{4}$ $(0.3 \mathrm{~mL})$ and concentrated acetic acid $(2.2 \mathrm{~mL})$ were successively added to a solution of sodium tungstate $\mathrm{Na}_{2} \mathrm{WO}_{4} 2 \mathrm{H}_{2} \mathrm{O}(12 \mathrm{~g})$ dissolved in water $(150 \mathrm{~mL})$. The white salt $\mathrm{Na}_{8} \mathrm{HPW}_{9} \mathrm{O}_{34} \cdot 24 \mathrm{H}_{2} \mathrm{O}$ precipitated out and was characterized by FTIR spectroscopy, and compared to the known spectrum $^{3}$.

Preparation and characterization of $\mathrm{B}-\mathrm{Na}_{8} \mathrm{HPW}_{9} \mathrm{O}_{34}$

The synthesis of $\mathrm{B}-\mathrm{Na}_{8} \mathrm{HPW}_{9} \mathrm{O}_{34}$ is a solid state thermal rearrangement of the $\left[\mathrm{A}-\mathrm{PW}_{9} \mathrm{O}_{34}\right]^{9-}$ isomer to mostly the $\left[\mathrm{B}-\mathrm{PW}_{9} \mathrm{O}_{34}\right]^{9-}$ form ${ }^{4}$. After obtaining the $\mathrm{A}-\mathrm{Na}_{8} \mathrm{HPW}_{9} \mathrm{O}_{34}$ as a white precipitate, it is first dried and then heated in an oven at $160 \mathrm{C}$ from 2 days to 1 week, or until the odor of acetic acid from the hot substance is no longer apparent. The conversion from A to B was monitored by IR spectroscopy ${ }^{3}$ (see text).

\section{Solution preparation}

Ultrapure water $(>18 \mathrm{M} \Omega \cdot \mathrm{cm})$ was used to make buffered electrolyte solutions $(1 \mathrm{M} \mathrm{NaCl}, 10$ $\mathrm{mM} \mathrm{NaH} \mathrm{PO}_{4}$ at various $\mathrm{pH}$ values from 5.5 to 7.1 ) for the single nanopore current recordings. The electrolyte solutions were filtered with a sterile $0.22 \mathrm{~mm}$ Millipore vacuum filter immediately prior to ion channel recordings. A $2 \mathrm{mM}$ phosphotungstic acid stock solution was prepared by dissolving $57.6 \mathrm{mg}$ into $10 \mathrm{~mL}$ of a $1 \mathrm{M} \mathrm{NaCl}$ and $10 \mathrm{mM} \mathrm{NaH}_{2} \mathrm{PO}_{4}$ solution the $\mathrm{pH}$ is then adjusted to 5.5, 6.0, 6.5, 7.1, 7.5, 8.0, 8.5, 9.0 by the addition of $3 \mathrm{M} \mathrm{NaOH}$, neglecting the dilution effect. A $2 \mathrm{mM} \mathrm{Na} 8 \mathrm{HPW}_{9} \mathrm{O}_{34}$ stock solution was prepared in buffered solutions containing $1 \mathrm{M} \mathrm{NaCl}$ and $10 \mathrm{mM} \mathrm{NaHCO}_{3}$. 


\section{Membrane formation and nanopore capture.}

The pore forming protein $\alpha-\mathrm{HL}$ was diluted to a $0.5 \mathrm{mg} / \mathrm{mL}$ solution in ultra-pure water and the $\mathrm{DPhPC}$ was dissolved in decane to $10 \mathrm{mg} / \mathrm{mL}$. Two $\mathrm{Ag} / \mathrm{AgCl}$ electrodes were prepared by soaking Ag wires in bleach, rinsed and dried, and then positioned inside and outside of a glass nanopore membrane (GNM) to apply a voltage. The GNM (radius between 700 and $1150 \mathrm{~nm}$ ) was painted on the GNM surface using a pipette tip with DPhPC solution $(1 \mu \mathrm{L}$ of $10 \mathrm{mg} / \mathrm{mL})$. The solution bath external to the glass capillary was coated with $0.6 \mu \mathrm{L}$ to $1.2 \mu \mathrm{L}$ of DPhyPC dissolved. After about $2 \mathrm{~min}$, the solution level was raised above the pore, spontaneously forming a membrane. Single pore ionic current measurements were obtained by allowing a single $\alpha$-HL pore to insert into the membrane by injecting $0.3 \mu \mathrm{L}$ of a 0.5 to $0.75 \mathrm{mg} / \mathrm{mL}$ solution of a preformed $\alpha$-HL and applying a slight back pressure $(\approx 80 \mathrm{~mm} \mathrm{Hg}$ to $110 \mathrm{~mm} \mathrm{Hg})$ from the capillary side to thin the membrane. After a single channel formed, the pressure was reduced to $\approx$ $20 \mathrm{~mm} \mathrm{Hg}$ to prevent further channel insertion. The measurements were performed at applied transmembrane potentials between -80 to $-120 \mathrm{mV}$ relative to channel trans to ensure a sufficiently high capture rate and for each $\mathrm{pH}$ with step of $20 \mathrm{mV}$. Data were recorded with a 500 $\mathrm{kHz}$ sampling rate. Positive potentials drive cations from the trans to the cis side of the membrane.

Ion Channel Recordings and Data Analysis.

A custom-built, high-impedance, low-noise amplifier and data acquisition system, designed and constructed by Electronic Biosciences (EBS), San Diego, CA, was used for the current time series recordings. About 200 capture/release events per second were collected under $120 \mathrm{mV}$ bias (trans versus cis) with a sampling rate of $500 \mathrm{kHz}$ after and filtered with an 8-pole Bessel filter with a $100 \mathrm{kHz}$ cutoff frequency. Ionic current traces were then analyzed with in-house software.

The electrical measurements are performed with the same $\mathrm{pHs}$ values used in the NMR experiments (from the stock solutions further diluted with a buffer solution) to a final POM concentration ranging from 1 to $30 \mu \mathrm{M}$ with a single $\alpha$-HL nanopore at 80,100 , and $120 \mathrm{mV}$ applied potential.

(1) Henrickson, S. E.; Misakian, M.; Robertson, B.; Kasianowicz, J. J. Phys. Rev. Lett. 2000, 85 (14), 3057-3060.

(2) Massart, R.; Contant, R.; Fruchart, J. M.; Ciabrini, J. P.; Fournier, M. Inorg Chem 1977, 16 (11), 2916-2921.

(3) Knoth, W. H.; Domaille, P. J.; Farlee, R. D. Organometallics 1985, 4 (1), 62-68.

(4) Randall, W. J.; Droege, M. W.; Mizuno, N.; Nomiya, K.; Weakley, T. J. R.; Finke, R. G.; Isern, N.; Salta, J.; Zubieta, J. In Inorganic Syntheses; Inorganic Syntheses; John Wiley \& Sons, Inc.: Hoboken, NJ, USA, 1996; Vol. 31, pp 167-185. 